\title{
Comparison of Outcome after Transurethral Resection of Small Versus Large Prostate in Benign Prostatic Hyperplasia
}

\author{
Harmandeep Singh Chahal' ${ }^{1}$, Simran Kaur ${ }^{2}$, Varun Mittal ${ }^{3}$, Maninder Jaura ${ }^{4}$, Namita Bansal ${ }^{5}$, Sandeep Sharma ${ }^{6}$ \\ ${ }^{1}$ Assistant Professor, Department of Urology, ${ }^{2}$ Assistant Professor, Department of Nephrology, ${ }^{3}$ Senior Resident, Department \\ of Urology, ${ }^{4}$ Former Senior Resident, Department of Urology, ${ }^{5}$ Statistician, Department of Research and Development, \\ ${ }^{6}$ Professor and HOD, Department of Urology, Dayanand Medical College, Ludhiana, Punjab, India
}

Corresponding author: Dr. Simran Kaur, Assistant Professor, Department of Nephrology, Dayanand Medical College, Ludhiana. 141001, India

DOI: http://dx.doi.org/10.21276/ijcmsr.2019.4.3.37

How to cite this article: Harmandeep Singh Chahal, Simran Kaur, Varun Mittal, Maninder Jaura, Namita Bansal, Sandeep Sharma. Comparison of outcome after transurethral resection of small versus large prostate in benign prostatic hyperplasia. International Journal of Contemporary Medicine Surgery and Radiology. 2019;4(3):C171C175.

\section{A B S T R A C T}

Introduction: Transurethral resection of prostate (TURP), remains the gold standard surgery for benign prostatic hyperplasia, but ideally recommended for prostate less than 80 grams, with option left open for larger sizes, subject to surgeon's expertise. The present study was aimed to prospectively compare the outcomes of TURP in small ( $\leq 80$ grams) versus large (>80 grams) prostatomegaly.

Material and methods: Peri-operative, immediate post-operative (before discharge), early (upto 1 month) and late (1 year post-op) complication, were compared between the two groups. A $p$-value less than 0.05 was taken as significant.

Result: Out of the total 162 patients undergoing TURP during the study period, 128 were enrolled, with 96 patients (mean age $71.7 \pm 10.2$, range $52-94$ years) completing 1 year of follow-up included in final analysis, and those with prostate size $\leq 80$ grams $(n=60$, mean size $51.8 \pm 11.8$, range $35-78$ ) were compared to those $>80$ grams $(n=36$, mean size $96.4 \pm 15.2$, range $82-140)$. Patients with larger prostates had worse pre-op International Prostate Symptom Score, $(p=0.000)$, more incidence of urinary tract infections $(p=0.050)$ and obstructive nephropathy $(p=0.023)$. They also had higher operative time $(p=0.000)$, peri-op fall in hemoglobin $(p=0.016)$, prolonged post-op catheterization $(p=0.000)$, need for recatheterization due to bladder clots $(p=0.023)$, longer hospital stay $(p=0.000)$, and higher rate of re-admission $(p=0.008)$ versus patients with small prostate. However, the long-term outcomes on 1 year follow-up were comparable in both the groups.

Conclusion: The size of prostate does impact the peri-operative and early post-op complications, but the long-term result are gratifying and comparable in small and large prostates.

Keywords: Benign Prostatic Hyperplasia (BPH), Transurethral Resection of Prostate (TURP), Small Prostate (<80 grams), Large Prostate (>80 grams), Peri-Operative Complication, Early Complications, Long-Term Complications.

\section{INTRODUCTION}

Lower urinary tract symptoms (LUTS) and voiding dysfunction due to benign prostatic hyperplasia $(\mathrm{BPH})$ affects approximately $50 \%$ men by the age of 50-60 years, and $90 \%$ by 80 years of age. ${ }^{1}$ Medical management is the first line of therapy, but surgery is recommended in patients refractory to medical management or in presence renal insufficiency, recurrent urinary tract infections, bladder calculi or gross hematuria. ${ }^{2}$ The choice of surgical technique among the transurethral approach, laser prostatectomy and open surgery is primarily based on size of the prostate, surgical expertise, feasibility of general anesthesia and patient's choice, besides unique challenges like infrastructural back-up and cost-implications in the developing world. Transurethral resection of prostate (TURP), the benchmark surgery for BPH, is ideally suggested for small to moderate sized prostate (30-80 gm), however the option is left open for larger prostates, subject to surgeon's experience, resection speed, and choice of resectoscope. . $^{3,4}$

The present study was aimed to prospectively compare the outcome of TURP in benign hyperplasia of small (less than 80 grams) versus large (more than 80 grams) prostates.

\section{MATERIAL AND METHODS}

This prospective study was done in a large tertiary care hospital in North India, in patients with BPH opting for transurethral resection of prostate. The study was approved by the institutional ethical committee and a written informed consent was taken from each patient before inclusion in the study. The diagnosis of BPH was based on medical history, physical examination, digital rectal examination, International Prostate Symptom Score (IPSS), ${ }^{6}$ Quality of life (QOL) score, ${ }^{6}$ serum prostate specific antigen (PSA) assay (nanograms per milliliter-ng/mL), ultrasonography (per-abdomen and/or trans-rectal) and uroflowmetry. 
Patients with neurogenic bladder, prostatic or bladder malignancy, urethral stricture, severe pre-morbidities (diabetics with $\mathrm{HbA1c}>7$ or known microvascular or macrovascular complications, coronary artery disease on clopidogrel therapy, chronic kidney disease or acute kidney injury, uncontrolled hypertension, liver disease) and known bleeding disorder were excluded.

Patients were operated under spinal anesthesia, in lithotomy position, using 24Fr monopolar resectoscope (Richard WOLF system), with normal saline irrigation. A $18 \mathrm{Fr}$ 3-way catheter was placed and continuous bladder irrigation was started immediately after surgery, and continued till irrigation yielded clear return for 6 hours, after which catheter was removed. Peri-operative and immediate postoperative parameters including operative time (insertion of the resectoscope to the insertion of the catheter), change/fall in hemoglobin, need for blood transfusion, catheterization time, immediate post-operative complications (urinary tract infection, bladder clots, need for re-catheterization, capsule or bladder perforation) and hospital stay were recorded with meticulous details. Patients were followed up at 7 days, 14 days and 1 month post-discharge for early complications, like UTI, secondary hemorrhage, bladder clots, need of readmission or re-surgery and transient incontinence (upto 1 month). For late complication, all the patient were followed up at 3 months, 6 months and 12 months postop for complaints like urinary (persistent or late onset) incontinence, retrograde ejaculation, persistent lower urinary tract symptoms (follow-up IPSS and QOL score), new-onset impotency, urethral stricture or bladder neck contraction, need for re-surgery in view of persistent LUTS.

\section{STATISTICAL ANALYSIS}

Data were described in terms of mean \pm standard deviation ( \pm $\mathrm{SD})$, frequencies (number of cases) and relative frequencies (percentages) as appropriate. Comparison of quantitative variables between the groups was done using Student t-test. For comparing categorical data, Chi square $(\chi 2)$ test was performed and exact test was used when the expected frequency was less than 5 . A probability value ( $p$ value) less than 0.05 was considered statistically significant. All statistical calculations were done using SPSS (Statistical

\begin{tabular}{|c|c|c|c|c|c|c|c|c|}
\hline \multirow[t]{2}{*}{ PRE-OPERATIVE PARAMETERS } & \multicolumn{2}{|c|}{$\leq 80(n=60)$} & \multicolumn{2}{|c|}{$>80(n=36)$} & \multirow[t]{2}{*}{$\mathbf{T}$} & \multirow[t]{2}{*}{ p-value } & \multicolumn{2}{|c|}{$\begin{array}{l}\text { 95\% Confidence } \\
\text { Interval of the } \\
\text { Difference }\end{array}$} \\
\hline & Mean & SD & Mean & SD & & & Lower & Upper \\
\hline Age (in years) & 73.15 & 10.36 & 69.33 & 9.53 & 1.800 & 0.075 & -0.39 & 8.03 \\
\hline $\begin{array}{l}\text { Pre-operative Prostate size } \\
\text { (in grams) }\end{array}$ & 51.75 & 11.76 & 96.39 & 15.23 & -16.089 & 0.000 & -50.15 & -39.13 \\
\hline Pre-operative IPSS score (total) & 19.05 & 0.93 & 21.36 & 2.27 & -6.991 & 0.000 & -2.97 & -1.65 \\
\hline 1. Incomplete evacuation & 2.90 & 1.15 & 2.75 & 1.02 & 0.646 & 0.520 & -0.31 & 0.61 \\
\hline 2. Frequency & 3.70 & 0.96 & 3.39 & 1.34 & 1.322 & 0.189 & -0.16 & 0.78 \\
\hline 3. Intermittency & 2.15 & 0.92 & 2.83 & 0.97 & -3.457 & 0.001 & -1.08 & -0.29 \\
\hline 4. Urgency & 2.20 & 0.68 & 2.94 & 1.01 & -4.297 & 0.000 & -1.09 & -0.40 \\
\hline 5. Weak Stream & 2.70 & 0.72 & 3.67 & 1.07 & -5.291 & 0.000 & -1.33 & -0.60 \\
\hline 6. Straining & 2.55 & 1.03 & 2.97 & 1.28 & -1.774 & 0.079 & -0.89 & 0.05 \\
\hline 7. Nocturia & 3.40 & 1.17 & 2.83 & 1.08 & 2.365 & 0.020 & 0.09 & 1.04 \\
\hline Pre-Operative QOL score & 4.62 & 0.96 & 5.25 & 0.73 & -3.411 & 0.001 & -1.00 & -0.26 \\
\hline Pre-operative Hemoglobin (grams/dl) & 12.15 & 1.56 & 12.64 & 1.26 & -1.618 & 0.109 & -1.11 & 0.11 \\
\hline Pre-operative PSA (ng/mL) & 2.98 & 1.02 & 3.99 & 5.17 & -1.474 & 0.144 & -2.38 & 0.35 \\
\hline Pre-operative S. Creatinine (mg/dl) & 1.09 & 0.62 & 1.21 & 0.79 & -0.836 & 0.405 & -0.41 & 0.17 \\
\hline \multirow{2}{*}{$\begin{array}{l}\text { Other parameters } \\
\text { (n=number of patients) }\end{array}$} & \multicolumn{2}{|c|}{$\leq 80(n=60)$} & \multicolumn{2}{|c|}{$>80(n=36)$} & \multirow{2}{*}{$\begin{array}{l}\text { Chi- } \\
\text { square } \\
\text { value }\end{array}$} & \multirow[t]{2}{*}{ p-value } & & \\
\hline & $\mathbf{n}$ & \%age & $\mathbf{N}$ & \%age & & & & \\
\hline Pre-operative medical therapy & 39 & $65.0 \%$ & 12 & $33.3 \%$ & 9.06 & 0.003 & & \\
\hline Finasteride & 39 & $65.0 \%$ & 2 & $5.6 \%$ & 32.494 & 0.000 & & \\
\hline Tamsulosin & 39 & $65.0 \%$ & 12 & $33.3 \%$ & 9.06 & 0.003 & & \\
\hline Pre-operative Aspirin therapy & 12 & $20.0 \%$ & 10 & $27.8 \%$ & 0.771 & 0.38 & & \\
\hline \multicolumn{9}{|l|}{ INDICATIONS FOR TURP } \\
\hline Failure of medical management & 33 & $55.0 \%$ & 12 & $33.3 \%$ & 4.242 & 0.039 & & \\
\hline Anxiety on Medical Management & 9 & $15.0 \%$ & 0 & $0.0 \%$ & 5.959 & 0.024 & & \\
\hline Bladder calculi & 3 & $5.0 \%$ & 1 & $2.8 \%$ & 0.278 & 0.598 & & \\
\hline Recurrent UTI & 6 & $10.0 \%$ & 9 & $25.0 \%$ & 3.84 & 0.050 & & \\
\hline Hematuria & 0 & $0.0 \%$ & 1 & $2.8 \%$ & 1.684 & 0.194 & & \\
\hline HUN & 0 & $0.0 \%$ & 3 & $8.3 \%$ & 5.161 & 0.023 & & \\
\hline Acute retention & 9 & $15.0 \%$ & 8 & $22.2 \%$ & 0.805 & 0.369 & & \\
\hline
\end{tabular}


Package for the Social Science) SPSS 21 version statistical program for Microsoft Windows.

\section{RESULT}

A total of 162 cases of prostatomegaly underwent TURP

\begin{tabular}{|c|c|c|c|c|c|c|c|c|}
\hline \multirow[t]{2}{*}{ Parameters } & \multicolumn{2}{|c|}{$\leq 80(n=60)$} & \multicolumn{2}{|c|}{$>80(n=36)$} & \multirow[t]{2}{*}{$T$} & \multirow[t]{2}{*}{ p-value } & \multicolumn{2}{|c|}{$\begin{array}{l}\text { 95\% Confidence } \\
\text { Interval of the Dif- } \\
\text { ference }\end{array}$} \\
\hline & Mean & SD & Mean & SD & & & Lower & Upper \\
\hline $\begin{array}{l}\text { Operative time } \\
\text { (in minutes) }\end{array}$ & 33.90 & 6.54 & 54.36 & 12.39 & -10.590 & 0.000 & -24.30 & -16.62 \\
\hline $\begin{array}{l}\text { Post-op Hemoglobin } \\
\text { (grams/dL) }\end{array}$ & 11.49 & 1.61 & 11.72 & 1.45 & -0.697 & 0.488 & -0.88 & 0.42 \\
\hline Decrease in $\mathrm{Hb}$ (grams/dL) & 0.66 & 0.48 & 0.92 & 0.58 & -2.462 & 0.016 & -0.48 & -0.05 \\
\hline Packed cell transfusions needed & 0.05 & 0.22 & 0.11 & 0.32 & -1.110 & 0.270 & -0.17 & 0.05 \\
\hline Post-op Catheterization days & 2.15 & 0.36 & 3.58 & 0.84 & -11.581 & 0.000 & -1.68 & -1.19 \\
\hline Post-operative serum creatinine (mg/dl) & 1.00 & 0.53 & 1.02 & 0.60 & -0.177 & 0.860 & -0.25 & 0.21 \\
\hline $\begin{array}{l}\text { Post-op Hospital stay } \\
\text { (days) }\end{array}$ & 2.40 & 0.49 & 4.22 & 1.27 & -9.972 & 0.000 & -2.19 & -1.46 \\
\hline \multirow[t]{2}{*}{ Other parameters ( $n=$ number of patients) } & \multicolumn{2}{|c|}{$\leq 80(n=60)$} & \multicolumn{2}{|c|}{$>80(n=36)$} & \multirow{2}{*}{$\begin{array}{l}\text { Chi- } \\
\text { square } \\
\text { value }\end{array}$} & \multirow[t]{2}{*}{ p-value } & & \\
\hline & $\mathbf{n}$ & \%age & $\mathbf{n}$ & \%age & & & & \\
\hline Post TURP Syndrome & 0 & $0.0 \%$ & 2 & $5.6 \%$ & 3.404 & 0.065 & & \\
\hline Need for Recatheterization & 0 & $0.0 \%$ & 3 & $8.3 \%$ & 5.161 & 0.023 & & \\
\hline Urinary bladder clot & 0 & $0.0 \%$ & 3 & $8.3 \%$ & 5.161 & 0.023 & & \\
\hline Need for re-surgery & 0 & $0.0 \%$ & 1 & $2.8 \%$ & 1.684 & 0.194 & & \\
\hline Post-Op UTI & 6 & $10.0 \%$ & 5 & $13.9 \%$ & 0.335 & 0.562 & & \\
\hline Readmission & 0 & $0.0 \%$ & 4 & $11.1 \%$ & 6.957 & 0.008 & & \\
\hline Transient incontinence & 9 & $15.0 \%$ & 8 & $22.2 \%$ & 0.805 & 0.369 & & \\
\hline Mortality & 0 & $0 \%$ & 0 & $0 \%$ & - & - & & \\
\hline \multicolumn{7}{|c|}{ TURP- Transurethral resection of prostate, UTI- Urinary tract infection } & & \\
\hline
\end{tabular}

\begin{tabular}{|c|c|c|c|c|c|c|c|c|}
\hline \multirow[t]{2}{*}{ Parameters } & \multicolumn{2}{|c|}{$\leq 80(n=60)$} & \multicolumn{2}{|c|}{$>80(n=36)$} & \multirow[t]{2}{*}{$T$} & \multirow[t]{2}{*}{ p-value } & \multicolumn{2}{|c|}{$\begin{array}{l}\text { 95\% Confidence Inter- } \\
\text { val of the Difference }\end{array}$} \\
\hline & Mean & SD & Mean & SD & & & Lower & Upper \\
\hline Post-operative IPSS score (total) & 4.85 & 0.73 & 4.72 & 0.78 & 0.808 & 0.421 & -0.19 & 0.44 \\
\hline 1. Incomplete evacuation & 0.80 & 0.40 & 0.81 & 0.40 & -0.065 & 0.948 & -0.17 & 0.16 \\
\hline 2. Frequency & 0.70 & 0.46 & 0.72 & 0.45 & -0.230 & 0.819 & -0.21 & 0.17 \\
\hline 3. Intermittency & 0.75 & 0.54 & 0.75 & 0.55 & 0.000 & 1.000 & -0.23 & 0.23 \\
\hline 4. Urgency & 0.75 & 0.44 & 0.69 & 0.47 & 0.588 & 0.558 & -0.13 & 0.24 \\
\hline 5. Weak Stream & 0.45 & 0.50 & 0.44 & 0.50 & 0.052 & 0.958 & -0.20 & 0.22 \\
\hline 6. Straining & 0.55 & 0.50 & 0.50 & 0.51 & 0.471 & 0.639 & -0.16 & 0.26 \\
\hline 7. Nocturia & 0.85 & 0.48 & 0.81 & 0.47 & 0.443 & 0.659 & -0.15 & 0.24 \\
\hline Post-op QOL score & 0.83 & 0.59 & 0.81 & 0.75 & 0.202 & 0.840 & -0.25 & 0.30 \\
\hline \multirow{2}{*}{$\begin{array}{l}\text { Other parameters } \\
\text { (n-number of patients) }\end{array}$} & \multicolumn{2}{|c|}{$\leq 80(n=60)$} & \multicolumn{2}{|c|}{$>80(n=36)$} & \multirow{2}{*}{$\begin{array}{c}\text { Chi- } \\
\text { square } \\
\text { value }\end{array}$} & \multirow[t]{2}{*}{ p-value } & & \\
\hline & $\mathrm{n}$ & \%age & $\mathbf{n}$ & \%age & & & & \\
\hline Urinary Incontinence & 4 & $6.7 \%$ & 4 & $11.1 \%$ & 0.58 & 0.446 & & \\
\hline New-onset erectile dysfunction & 6 & $10.0 \%$ & 4 & $11.1 \%$ & 0.03 & 0.863 & & \\
\hline Retrograde ejaculation & 6 & $10.0 \%$ & 4 & $11.1 \%$ & 0.03 & 0.863 & & \\
\hline Stricture urethra & 0 & $0 \%$ & 0 & $0 \%$ & - & - & & \\
\hline Bladder neck contracture & 0 & $0 \%$ & 0 & $0 \%$ & - & - & & \\
\hline Significant post-void residual urine & 0 & $0 \%$ & 0 & $0 \%$ & - & - & & \\
\hline \multicolumn{9}{|c|}{ IPSS-International Prostate Symptom Score, QOL-Quality of life } \\
\hline
\end{tabular}


during the study period ( $1^{\text {st }}$ January 2017 to $31^{\text {st }}$ December 2017), 128 patients that met the inclusion criteria, and operated by the same surgeon, were included in the study. Detailed demographic data, history, and evaluation of all patients was recorded, and their operative parameters, postoperative hospital course and complications were noted in detail. Patients were followed up at day 7 and 14 postdischarge and then at 1, 3, 6 and 12 months. Only patients who completed 12 months of follow-up ( $\mathrm{N}=96)$ were included for final analysis. The mean age of the total cohort was $71.7 \pm 10.2$ (range 52 to 94 years). The data of patients with prostate size less than 80 grams $(n=60)$ was compared to those with baseline size more than 80 grams $(n=36)$. The mean size of prostate in the two groups was $51.8 \pm 11.8$ ( 35 to 78 grams) and $96.4 \pm 15.2$ grams ( 82 to 140 grams) $(\mathrm{p}=0.000)$. Patients with larger prostates had worse baseline IPSS scores $(p=0.000)$, more incidence of UTI $(p=0.050)$ and obstructive nephropathy changes $(\mathrm{p}=0.023)$ as indication for surgery (Table 1$)$. They had significantly higher operative time $(p=0.000)$, fall in hemoglobin peri-op $(p=0.016)$, prolonged post-op catheterization to achieve hemostasis $(p=0.000)$, need for recatheterization due to bladder clot $(\mathrm{p}=0.023)$ and also lead to significantly longer hospital stay (4.2 \pm 1.3 days versus $2.4 \pm 0.5$ days; $\mathrm{p}=0.000)$, and higher rate of re-admission ( 4 vs $0 ; p=0.008$ ) versus patients with small prostate (Table 2). However on 1 year of follow-up, the IPSS and QOL score, and other long-term outcomes were comparable in both the groups (Table 3).

\section{DISCUSSION}

Since the first TURP performed by Guyon in 1901 in Paris, the technique has established itself as the gold standard for the treatment of BPH, due to its cost-effectiveness and low complication rate. ${ }^{6}$ The European Association of Urology guidelines advocate TURP in small to moderate sized prostatomegaly (less than 80 grams), but keeps option open for large sized (> 80 grams) prostate, subject to surgeon's competence. ${ }^{7}$ The trends in developed countries, like United States, are showing a sharp decline in the rate of TURP $(81 \%$ to $39 \%$ from 1999 to 2005 ), due to advent of minimal invasive procedures, ${ }^{8}$ but the developing world often faces compelling circumstances like limited infrastructural resources and poor patient affordability for laser procedures, besides the universal reluctance for open surgery and often have to go for TURP in all prostates sizes. A previous study has compared small number of patients, but had shorter follow-up 9 and another Romanian study has previously compared TURP with open prostatectomy in large prostate (with almost half of TURP procedures done as two stage procedures).$^{10}$ This prospective study has systematically compared the immediate, early and long-term outcomes after TURP in small ( $\leq 80$ grams) versus large ( $>80$ grams) prostate.

In our study, many of the patients with small prostate had been on medical management and failed conservative trial before opting for TURP, however larger sized were lesser likely to be offered option of medical management, and few who opted were bold enough, not to feel anxious with their choice. The larger size correlated with worse IPSS scores $(p=0.000)$, and more incidences of UTI $(p=0.050)$ and obstructive nephropathy ( $\mathrm{p}=0.023)$.

Although surgical time in our study was significantly higher in larger sized prostates versus the smaller ones (54.36 \pm 12.39 vs $33.9 \pm 6.54, p=0.000)$, risk of post-TURP syndrome did not increase $(p=0.065)$. The resection time $(50 \mathrm{mins})$ and post-TURP syndrome for large prostates was comparable to TURP group in Romanian ${ }^{10}$ and Jordan series. ${ }^{11}$ The study from Jordan had reported $72 \pm 6.2$ minutes resection time for sizes more than 80 grams, ${ }^{11}$ and the series from Kathmandu had comparatively very high resection time for both small and large prostate groups $(110 \pm 15$ vs $90 \pm 20){ }^{9}$

Longer resection time in large prostate volume subjects of our study meant more bleeding and greater fall in hemoglobin $(\mathrm{p}=0.016)$, and larger raw bleeding area requiring prolonged post-op catheterization till hemostasis was achieved (3.58 \pm 0.84 vs $2.15 \pm 0.36, p=0.000$ ). The fall in hemoglobin in the large prostate group in our study $(0.92 \pm 0.58 \mathrm{mg} / \mathrm{dl})$ was less than that encountered by Al-Hammouri et al $(3.2 \pm 0.6 \mathrm{mg} /$ dl) in same size group. ${ }^{11}$

In early complications, a few, but statistically significant number of patients with large prostate, developed bladder clots after catheter removal and needed recatheterization $(\mathrm{p}=0.023)$, with an occasional one needing clot evacuation $(p=0.194)$. This lead to a comparatively longer hospital stay (4.2 \pm 1.3 days versus $2.4 \pm 0.5$ days; $p=0.000)$, and higher rate of readmission ( 4 vs $0 ; \mathrm{p}=0.008$ ) in large prostate cohort. The complications were comparable to Jordan experience, ${ }^{11}$ however, the hospital stay was less as compared to $6.08 \pm 4.01$ and $4.80 \pm 1.47$ days in the previous study comparing small and large prostate TURP. ${ }^{9}$

Transient incontinence for first three months was encountered in more than one-third (38\%) patients after TURP in Romanian cohort, ${ }^{10}$ however only $22 \%$ in our study had this problem which improved significantly by 1 year of follow-up.

On long term follow-up, the large prostate cohort had a significant relief $(p=0.000)$ in lower urinary tract symptoms, with IPSS scores at 1 year post-surgery comparable in both the groups $(\mathrm{p}=0.421)$. There was no increased incidence of new-onset erectile dysfunction, retrograde ejaculation, or other complications. Some previous studies have reported an incidence of post TURP urethral stricture from $2.2 \%$ to $9.2 \%$ and bladder neck contracture in 0.3 to $9.2 \%{ }^{11,12,13,14}$ Joshi et al reported regular use of internal urethrotomy (Otis), ${ }^{9}$ but still a post TURP urethral stricture occurred in $5.7 \%$ from small prostate, ${ }^{9}$ and $6 \%$ in Jordan series of large prostate $^{11}$ who required further intervention by Optical Internal urethrotomy (OIU), which was hypothesized to be due to their prolonged operative time. There were no stricture urethra and bladder neck contractures on follow up in any of our patients. None of the patients needed re-surgery for residual prostate due to significant PVRU, whereas $2 \%$ had a re-do TURP in Jordan series, ${ }^{11}$ and $42 \%$ needed two stage resection in Persu et al study. ${ }^{10}$

As any other study, this study too has its strengths and limitations. This study has fairly good patient number and long follow-up, with meticulous monitoring for intra-op and post-op complications. However, a still larger study will help in establishing the supremacy of TURP even better, especially 
with a head on comparison to open surgery in large prostate too, whereby the complications and cost implications of these two techniques can also be compared.

\section{CONCLUSION}

Transurethral resection of prostate can be successfully done in all sizes of benign prostate hyperplasia, as barring few immediate/early hitches, the long term prognosis is fairly good in large prostates operated with TURP, and results comparable with small and moderate sized prostate. This study will instill confidence in urological surgeons for using TURP in all prostate sizes, especially while working in developing countries like ours, with limited resources and infrastructures, as well as poor patient affordability for long hospitalization associated with open surgeries.

\section{REFERENCES}

1. Thorpe A, Neal D. Benign prostatic hyperplasia. Lancet 2003; 361(1): 1359-67.

2. McVary KT, Roehrborn CG, Avins AL, Barry MJ, Bruskewitz RC, Donnell RF, et al. Update on AUA guideline on the management of benign prostatic hyperplasia. J Urol. 2011;185(5):1793-803.

3. Oelke, M. Bachmann A, Descazeaud A, Emberton M, Gravas S, Michel MC et al. EAU guidelines on the treatment and follow-up of non-neurogenic male lower urinary tract symptoms including benign prostatic obstruction. Eur. Urol. 2013; 64(3): 118-40.

4. Pujari NR. Transurethral Resection of Prostate is Still the Gold Standard for Small to Moderate Sized Prostates. J Integr Nephrol Androl 2016;3(6):68-9.

5. Abáigar-Pedraza I, Pelluch-Auladell AM, GalianoBaena JF, Mira-Moreno A, Bravo-López DF, LobatoEncinas JJ. Quality of life in patients with benign prostatic hyperplasia (bph): endoscopic surgery versus laser therapy. Surg Techniques, Arch. Esp. Urol. 2014; 67 (10): 823-830

6. Gupta NP, Anand A. Comparison of TURP, TUVRP, and HoLEP. Curr Urol Rep 2009;10(4):276-8.

7. Gravas S, Cornu JN, Drake MJ, Gacci M, Gratzke C, Herrmann TRW et al. EAU Guidelines on management of non-neurogenic male lower urinary tract symptoms (LUTS). European Association of Urology 2018.

8. Yu X, Elliott SP,Wilt TJ,McBean AM. Practice patterns in benign prostatic hyperplasia surgical therapy: the dramatic increase in minimally invasive technologies. J Urol. 2008;180:241-5.

9. Joshi HN, de Jong IJ, Karmacharya RM, Shrestha B, Shrestha R. Outcomes of Transurethral Resection of the Prostate in Benign Prostatic Hyperplasia Comparing Prostate size of more than 80 Grams to Prostate Size less than 80 Grams. Kathmandu Univ Med J 2014;47(3):163-7.

10. Persu C, Georgescu D, Arabagiu I, Cauni V, Moldoveanu C, Geavlete P. TURP for BPH. How Large is Too Large? J Med Life. 2010; 3(4): 376-80.

11. Al-Hammouri F, Abu-Qamar A. Monopolar Transurethral resection of the big prostate, experience at Prince Hussein Bin Abdullah Urology Centre. JPMA 2011; 61(1): 628-31.

12. Mebust WK, Holtgrewe HL, Cockett AT, Peters
PC. Transurethral Prostatectomy: immediate and postoperative complications. A cooperative study of 13 participating institutions evaluating 3,885 patients. J Urol 1989; 141(5):243-7.

13. TascI AI, Ilbey YO, Tugcu V, Cicekler O, Cevik C, Zoroglu F. Transurethral resection of the prostate with monopolar resectoscope: single surgeon experience and long term results after 3589 procedures. Urology 2011;78(6):1151-5.

14. Kuntz RM, Ahyai S, Lehrich K, Fayad A. Transurethral holmium Laser enucleation of the prostate versus transurethral electrocautery resection of the prostate: a randomized prospective trial in 200 patients. J Urol 2004; 172(2): 1012-6.

\section{Source of Support: Nil; Conflict of Interest: None}

Submitted: 08-08-2019; Accepted: 05-09-2019; Published online: 13-09-2019 